\title{
Human rpL3 plays a crucial role in cell response to nucleolar stress induced by 5-FU and L-OHP
}

\author{
Davide Esposito ${ }^{1,2}$, Elvira Crescenzi ${ }^{3}$, Vinay Sagar ${ }^{4}$, Fabrizio Loreni ${ }^{4}$, \\ Annapina Russo ${ }^{5, *}$, Giulia Russo ${ }^{5, *}$ \\ ${ }^{1}$ Department of Molecular Medicine and Medical Biotechnology, University of Naples "Federico II", Naples 80131, Italy \\ ${ }^{2}$ Department of Oncological Sciences, Icahn School of Medicine at Mount Sinai, New York, NY, USA \\ ${ }^{3}$ Institute of Experimental Endocrinology and Oncology-CNR, Naples 80131, Italy \\ ${ }^{4}$ Department of Biology, University of Rome 'Tor Vergata', Rome 00133, Italy \\ ${ }^{5}$ Department of Pharmacy, University of Naples "Federico II", Naples 80131, Italy \\ *These authors contributed equally to this publication and share last authorship
}

Correspondence to:

Giulia Russo, e-mail: giulia.russo@unina.it

Annapina Russo, e-mail: annapina.russo@unina.it

Keywords: p21, ribosomal protein, 5-FU, Oxaliplatin, DNA repair

Received: August 18, $2014 \quad$ Accepted: October 11, $2014 \quad$ Published: November 28, 2014

\section{ABSTRACT}

Recent evidence showed that a variety of DNA damaging agents including 5-FU and L-OHP impairs ribosomal biogenesis activating a ribosomal stress pathway. Here, we demonstrate that in lung and colon cancer cell lines devoid of p53, the efficacy of 5-FU and L-OHP chemotherapy depends on rpL3 status. Specifically, we demonstrate that ribosomal stress induced by 5-FU and L-OHP is associated to up-regulation of rpL3 and its accumulation as ribosome-free form. We show that rpL3 participates in the cell response to chemotherapy acting as a critical regulator of cell cycle, apoptosis and DNA repair, by modulating p21 expression. Moreover, we demonstrate that rpL3 is able to control DNA repair also independently from p21 status of cell. It is noteworthy that silencing of rpL3 abolishes the cytotoxic effects of 5-FU and L-OH indicating that the loss of rpL3 makes chemotherapy drugs ineffective. Taking together our results shed light on 5-FU and L-OHP mechanism of action and contribute to more effective clinical use of these drugs in cancer therapy.

\section{INTRODUCTION}

A major role of nucleolus is the production of small and large ribosome subunits; however as involved in additional cellular functions, provides a link between ribosome subunits biosynthesis, cell cycle progression and stress signaling [1-3]. Recently, some evidence, indicate that 5-fluouracil (5-FU) and Oxaliplatin (L-OHP) represent two chemotherapeutic molecules exerting inhibitory effect on ribosome biogenesis [4]. Three different levels for perturbation of ribosome biogenesis by chemotherapeutic drugs have been defined, i.e. inhibition of rRNA gene transcription, inhibition of early and late maturation of rRNA precursors, and perturbation linked to disintegration of nucleolar structures [5-7]. Drugs which inhibit the rRNA transcription and early processing of 32S rRNA precursor, such as L-OHP, promote the nucleoplasmic translocation of nucleophosmin (NPM), a well-known marker of nucleolar disruption [8]. However, nucleolar breakdown does not seem to be an essential step for activation of the ribosomal stress pathway. In fact, 5-FU, which inhibits rRNA late processing steps, does not induce NPM translocation into the nucleoplasm.

5-FU and L-OHP are widely used for therapy of a variety of solid tumors. Increased understanding of the mechanism of action of these two drugs has led to the development of strategies that enhance their anticancer activity. Despite these advances, response rates to 5-FU-based chemotherapy, alone or in combination with L-OHP, does not exceed 40-50\%. In addition, development of drug resistance during the therapy remains a major problem [9]. 
During the last few years, the effects of 5-FU on cell growth arrest and apoptosis have been attributed to a p53-dependent stress signaling pathway, activated in response to disruption of ribosomal biogenesis [10]. This type of p53-activating stimulus involves a subset of ribosomal proteins (rp), including $\mathrm{rpL} 11, \mathrm{rpL} 23, \mathrm{rpL} 5$, $\operatorname{rpS} 7$ [11]. These proteins affect human double minute-2 (HDM2)-p53 circuit and lead to accumulation of p53 causing p53-dependent cell-cycle arrest [12-14].

It is known that most cancer cells contain mutant p53 or no p53 at all $[15,16]$. In recent years, some data revealed the existence of p53-independent mechanisms involving ribosomal proteins that link nucleolar stress to cell cycle arrest [17-19].

We have studied post-transcriptional regulatory strategies of mammalian ribosomal proteins (r-proteins), and we demonstrated that human rpL3 autoregulates its own expression through alternative splicing associate to nonsense-mediated mRNA decay. We have also identified hnRNP H1, NPM and KHSRP as transacting factors involved in the regulation of the alternative splicing of rpL3 gene and analysed their role in rpL3 autoregultory circuit [20].

We have recently demonstrated that human rpL3 exerts an extra-ribosomal function resulting in the induction of p21-dependent cell growth arrest and apoptosis in the absence of p53 [21]. In this paper, we demonstrate that ribosome-free rpL3 plays a critical role in cell response to ribosome stress induced by 5-FU and L-OHP treatments. Our data show that rpL3 is involved in drug-induced cell-cycle arrest, apoptosis and DNA repair by controlling p21 expression. In addition, rpL3 is also able to control DNA repair in a p21-independent manner. Finally, we report that the absence of rpL3 is dramatically associated to ineffectiveness of 5-FU and L-OHP.

\section{RESULTS}

\section{5-FU and L-OHP treatments increase the ribosome-free form of $\mathrm{rpL3}$}

Ribosome biogenesis represents a target for a large variety of drugs for cancer therapy [3, 22]. It is known that upon drug-induced ribosomal stress some r-proteins accumulate as ribosome-free forms and induce cell growth arrest and apoptosis [14, 23-25]. To understand whether drug-induced ribosomal stress caused the accumulation of ribosome-free rpL3, we treated Calu-6 and HCT 116 p53-/- cells with $100 \mu \mathrm{M}$ of 5-FU or $10 \mu \mathrm{M}$ of L-OHP corresponding to the concentrations for the complete inhibition of rRNA late processing steps or rRNA gene transcription, respectively [4]. $24 \mathrm{~h}$ after treatments, cells were collected, lysed (total fraction, TF) and fractionated to obtain the ribosome-associated fraction (RF) and the ribosome-free fraction (FF) [19]. Proteins extracted from each fraction were analyzed by western blotting.
Figures $1 \mathrm{a}$ and $1 \mathrm{~b}$ show that 5-FU and L-OHP treatments caused an increase of total rpL3 level and a significant accumulation of ribosome-free rpL3. 5-FU or L-OHP failed to increase the levels of $\operatorname{rpL} 7 \mathrm{a}$ and $\mathrm{rpS19}$, two arbitrary proteins of large and small subunit respectively, which remained largely associated to the ribosome (Figures 1a and 1b).

\section{rpL3 is involved in the cell response to 5-FU and L-OHP}

In order to understand whether the ribosome-free rpL3 could be involved in the cell response to 5-FU and L-OHP, we analyzed the influence of rpL3 on druginduced cell cycle modifications and apoptosis. To this aim, we impaired rpL3 function by incubating Calu-6 and HCT 116 p53-/- cells with siRNA specific for rpL3. Then, cells were treated with $100 \mu \mathrm{M}$ of 5 -FU or $10 \mu \mathrm{M}$ of L-OHP. $24 \mathrm{~h}$ later, rpL3 protein levels were detected by western blotting (Supplementary Figure 1) and cell cycle was analyzed by flow cytometry. The tested drugs exerted different effects on the cell cycle. In the presence of rpL3 (scrambled siRNA), the addition of $100 \mu \mathrm{M}$ of $5-\mathrm{FU}$ caused S phase arrest, whereas incubation with $10 \mu \mathrm{M}$ of L-OHP completely prevented cells to undergo DNA synthesis. Of interest, the depletion of rpL3 (rpL3 siRNA) restored normal cell cycle distribution in 5-FU or L-OHPtreated cells. Note that in untreated cells, the silencing of rpL3 did not affect the cell cycle (Figures $2 \mathrm{a}$ and $2 \mathrm{~b}$ ).

Analogous experiments were performed by using low doses of ActD. To this purpose, Calu- 6 cells were transiently transfected with rpL3 siRNA or scrambled siRNA. Then, cells were treated with ActD $5 \mathrm{nM}$ for $24 \mathrm{~h}$ and cell cycle was analyzed by flow cytometry. As shown in Supplementary Figure 2 the depletion of rpL3 (rpL3 siRNA) restored normal cell cycle distribution in ActDtreated cells.

To study the role of ribosome-free $\mathrm{rpL} 3$ in the apoptotic response to 5-FU and L-OHP, modifications of mitochondrial inner membrane potential $(\Delta \Psi \mathrm{m})$ were estimated by tetramethylrhodamine ethyl ester (TMRE) staining [26]. Calu-6 and HCT 116 p53-/- cells were transiently transfected with rpL3 siRNA or scrambled siRNA. Then, cells were treated with $100 \mu \mathrm{M}$ of $5-\mathrm{FU}$ or $10 \mu \mathrm{M}$ of L-OHP for $24 \mathrm{~h}$ TMRE-stained cells were analyzed by flow cytometry. As expected, the percentage of apoptosis increased after 5-FU or L-OHP treatments compared to control in each cell lines (Figures $3 a$ and $3 b$ ). Interestingly, rpL3 silencing resulted in a decrease of apoptotic cells following 5-FU or L-OHP treatments (Figures $3 \mathrm{a}$ and $3 \mathrm{~b}$ ).

These data suggest that rpL3 was needed to mediate 5-FU and L-OHP apoptotic cell response.

Next, we performed a clonogenic assay. To this aim, Calu-6 cells were transiently transfected with $\mathrm{rpL} 3$ siRNA or scrambled siRNA and treated with $100 \mu \mathrm{M}$ of 

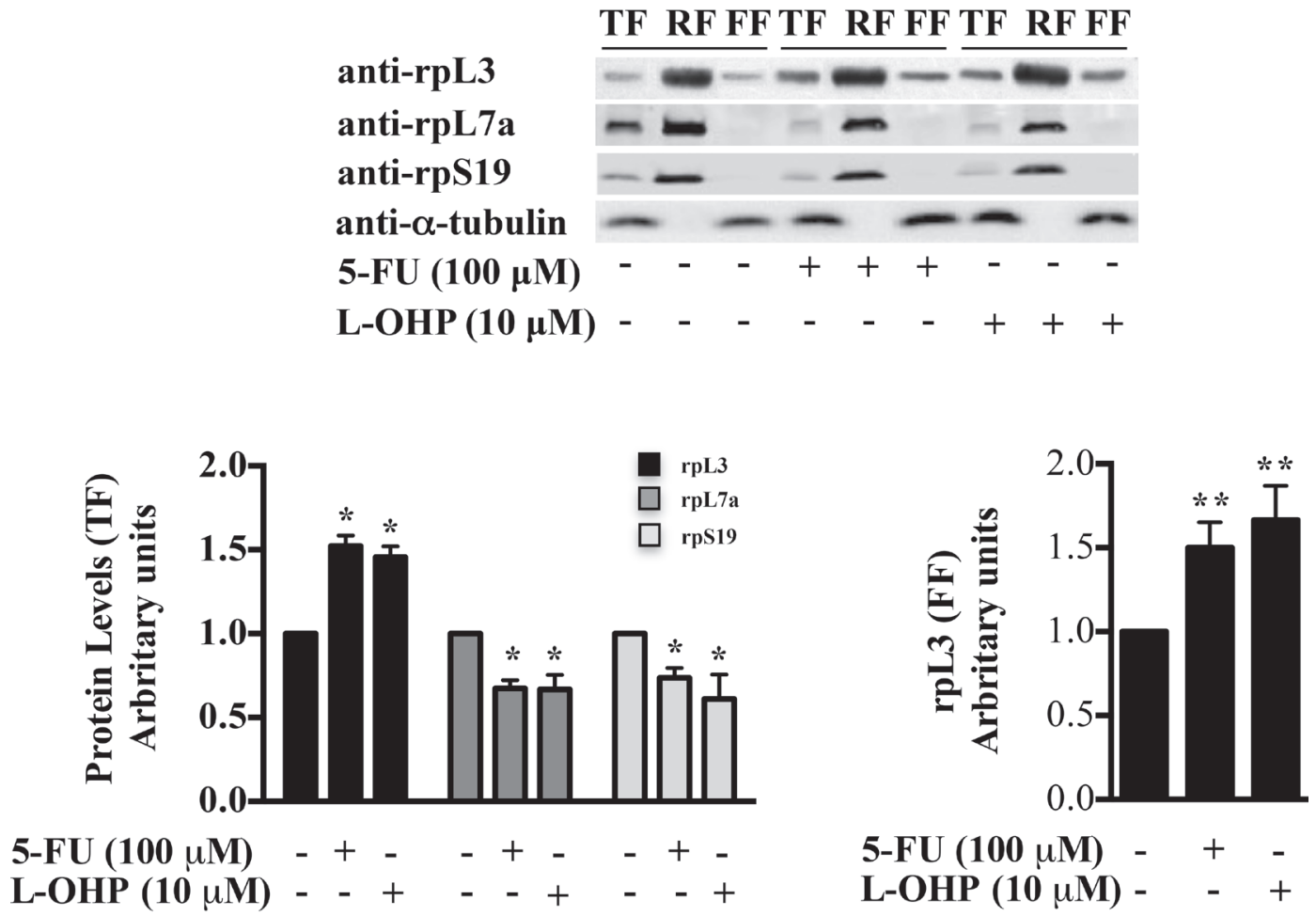

5-FU $(100 \mu \mathrm{M})-\quad+\quad-$

L-OHP $(10 \mu \mathrm{M})-\quad-\quad+\quad-\quad+\quad-\quad-\quad+$

L-OHP (10 $\mu \mathrm{M})-\quad-\quad+$

b

HCT 116 p53 -/- cells

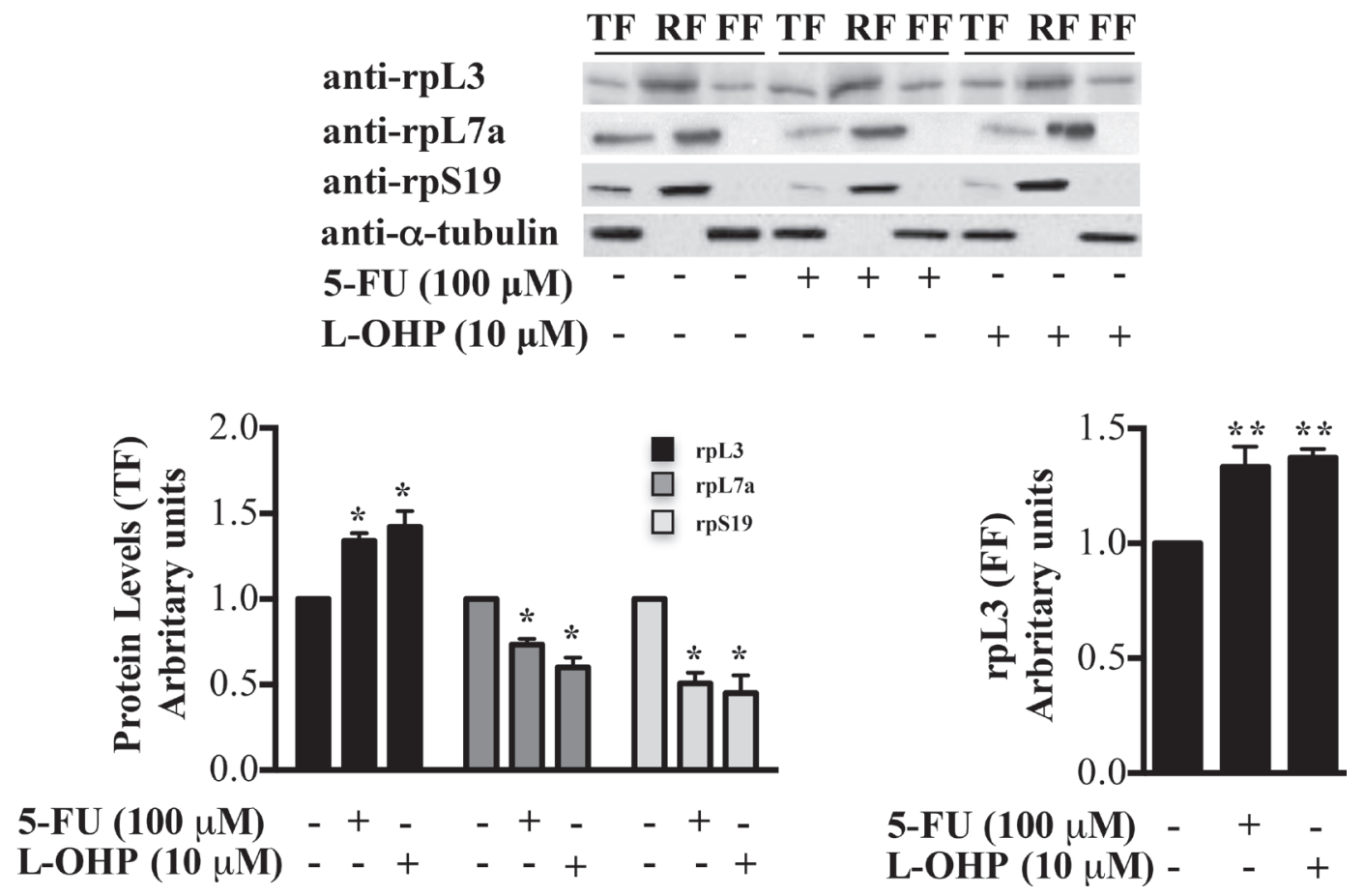

Figure 1: Distribution profile of rpL3 protein upon drug treatments. (a) Calu- 6 cells, untreated and treated with $100 \mu \mathrm{M} 5-\mathrm{FU}$ or $10 \mu \mathrm{M} \mathrm{L-OHP}$ for $24 \mathrm{~h}$, were collected, lysed (total fraction, TF) and fractionated to obtained the ribosome-associated fraction (RF) and ribosome-free fractions (FF). The fractions were analyzed by western blotting with the indicated antibodies. The per-cell ratio of the amount of protein loaded onto a gel was TF:RF:FF/1:10:1. Quantification of rpL3, rpL7a and rpS19 in TF (panel on the left) and quantification of rpL3 in FF (panel on the right) are shown. (b) Results from analogous experiments performed in HCT 116 p53-/- cells are shown. Results illustrated in Figures 1-8 are representative of three independently performed experiments. 


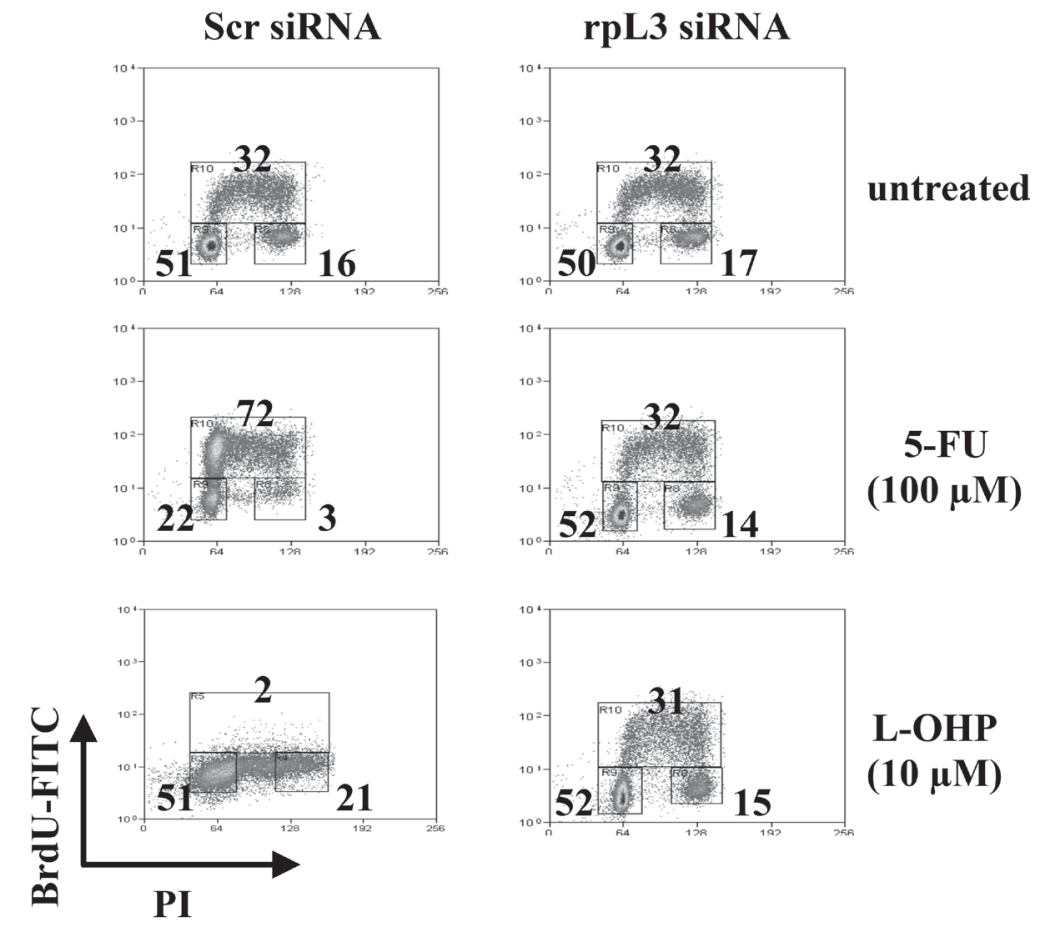

b

HCT 116 p53-/- cells
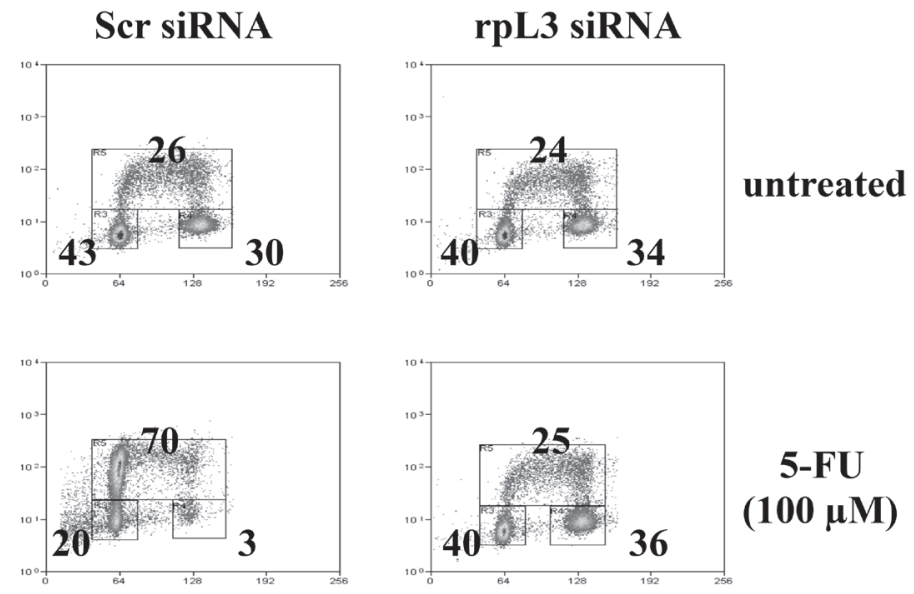

5-FU

$(100 \mu \mathrm{M})$
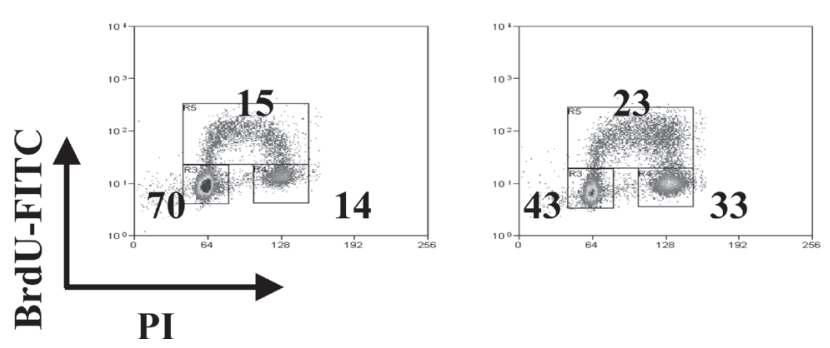

L-OHP

$(10 \mu \mathrm{M})$

Figure 2: Effect of rpL3 silencing on cell cycle upon 5-FU and L-OHP treatments. (a) Calu-6 cells and (b) HCT 116 p53-/- cells were transiently transfected with siRNA specific for rpL3 or scrambled siRNA (Scr) and treated with 5-FU or L-OHP for $24 \mathrm{~h}$ or untreated. Cells were stained with FITC conjugated anti-5-bromodeoxyuridine antibodies and counterstained with propidium iodide to analyze DNA synthesis and DNA content respectively by flow cytometry. The percentage of cells in different phases of cell cycle is shown. 

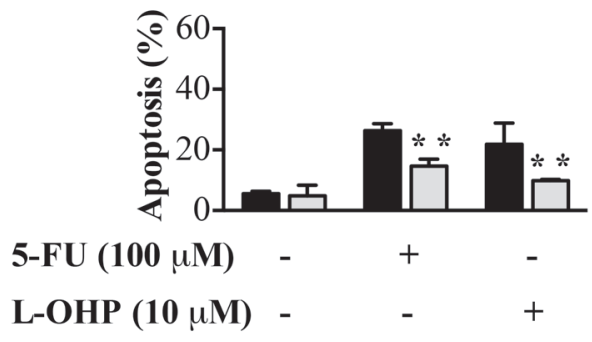

b

HCT 116 p53-/- cells

Ser siRNA

$\square$ rpL3 siRNA

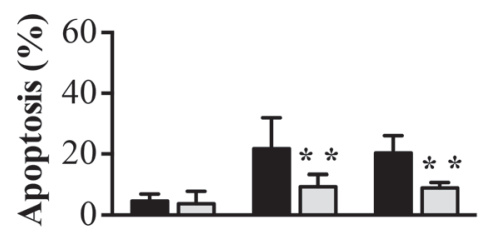

5-FU $(100 \mu \mathrm{M}) \quad-\quad+$

L-OHP $(10 \mu M)$ - $\quad$ - $\quad+$

\author{
Calu-6 cells
}

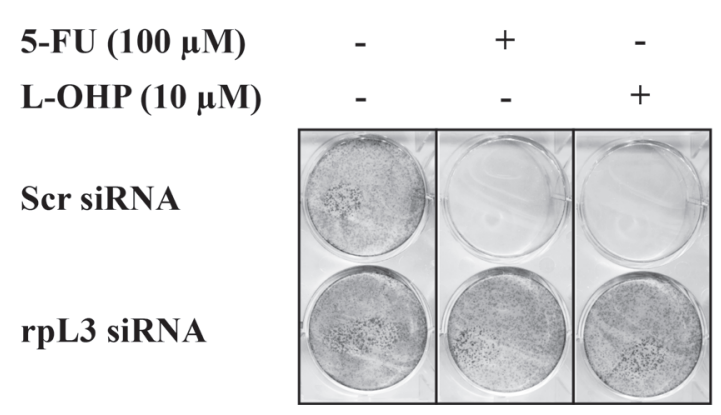

Figure 3: Effect of rpL3 silencing on apoptosis and cell survival upon 5-FU and L-OHP treatments. (a) Calu-6 cells and (b) HCT 116 p53-/- cells were transiently transfected with siRNA specific for rpL3 or scrambled siRNA (Scr) and treated with 5-FU or L-OHP for $24 \mathrm{~h}$ or untreated. Then cells were analyzed for mitochondrial membrane potential by TMRE staining. Fluorescence was measured by flow cytometry. (c) Clonogenic assay. Calu-6 cells transiently transfected with siRNA for rpL3 or scrambled siRNA (Scr) were treated with 5-FU or L-OHP for $24 \mathrm{~h}$ or untreated. After 10 days, colonies were stained with methylene blue, counted and photographed.

5-FU or $10 \mu \mathrm{M}$ of L-OHP for $24 \mathrm{~h}$. In cells transfected with scrambled siRNA, the colony number was strongly reduced upon exposure to 5-FU or L-OHP thus confirming the ability of the drugs to inhibit clonogenicity. It is noteworthy that following rpL3 depletion the capacity of cells to produce colonies upon 5-FU and L-OHP treatments was comparable to the capacity of untreated cells transfected with scrambled siRNA (Figure 3c).

\section{rpL3 is involved in DNA damage induction}

In order to analyze whether rpL3 was involved in the DNA damage induction we mesaured the amount of $\mathrm{H} 2 \mathrm{AX}$ phosphorylation at serine 139 (termed $\gamma-\mathrm{H} 2 \mathrm{AX}$ ), a central component of various signaling pathways in response to DSBs [27]. To this aim, Calu-6 and HCT 116 p53-/- cells were transiently transfected with rpL3 siRNA, scrambled 
siRNA or pHA-rpL3, a plasmid encoding rpL3-HA. Then, cells were treated with $100 \mu \mathrm{M}$ of $5-\mathrm{FU}$ or $10 \mu \mathrm{M}$ of L-OHP for $24 \mathrm{~h}$. Figure 4 showed that in untreated cells the depletion of rpL3 did not cause an increase of DNA damage. In fact, in this condition the levels of $\gamma$-H2AX were similar to those observed in untreated cells transfected with scrambled siRNA. In contrast, an increase of $\gamma-\mathrm{H} 2 \mathrm{AX}$ amounts was detected in untreated cells after rpL3 over-expression. As expected, the exposure of cells to 5-FU and L-OHP induced an increase of $\gamma-\mathrm{H} 2 \mathrm{AX}$ levels. The overexpression of $\mathrm{rpL} 3$ in these cells caused an additional increase of $\gamma-\mathrm{H} 2 \mathrm{AX}$ indicating that $\mathrm{rpL} 3$ is able to increase DNA damage induced by 5-FU or L-OHP treatment. Of interest, the specific silencing of rpL3 abolished DNA damage caused by 5-FU and L-OHP in each cell line (Figure 4).

\section{rpL3 is involved in HR and NHEJ pathways}

In mammals, the formation of DSBs is repaired mainly through two pathways, the homologous recombination (HR) and non homologous end joining (NHEJ) [28, 29]. We assessed the proficiency of cells for $\mathrm{HR}$ and NHEJ in conditions of rpL3 silencing. In order to study HR, HeLa/DR-GFP cells (see Materials and Methods) were transiently co-transfected with a plasmid expressing I-SceI endonuclease and rpL3 siRNA or scrambled siRNA (Supplementary Figure 3). 48 h posttransfection, cells were harvested and subjected to GFP flow cytometry. Figure 5a shows that the depletion of rpL3 was associated to an increase of GFP+ cells versus cells transfected with scrambled siRNA.

To examine the involvement of $\mathrm{rpL} 3$ in NHEJ, Calu-6 and HCT 116 p53-/- cells were used in a plasmid end-joining assay by using transient transfection of pGL3 plasmid linearized with HindIII or NarI (see Materials and Methods). DNA repair via NHEJ was measured by relative luciferase activity. We observed that depletion of rpL3 affected luciferase production in each cell line (Figures 5b and 5c). Of interest, a significant increase of precise (error-free) DNA EJ activities in cells silenced for rpL3 compared to cells treated with scrambled siRNA was observed (Figure $5 \mathrm{c}$ ). To better assess the role of rpL3 in the regulation of HR and NHEJ we evaluated the effect of rpL3 on DNA damage after the inhibition of DNA-PK, an essential component of both DNA repair pathways. To this aim, Calu-6 and HCT 116 p53-/- cells were transiently depleted of rpL3 by using specific siRNAs, and DNA-PK

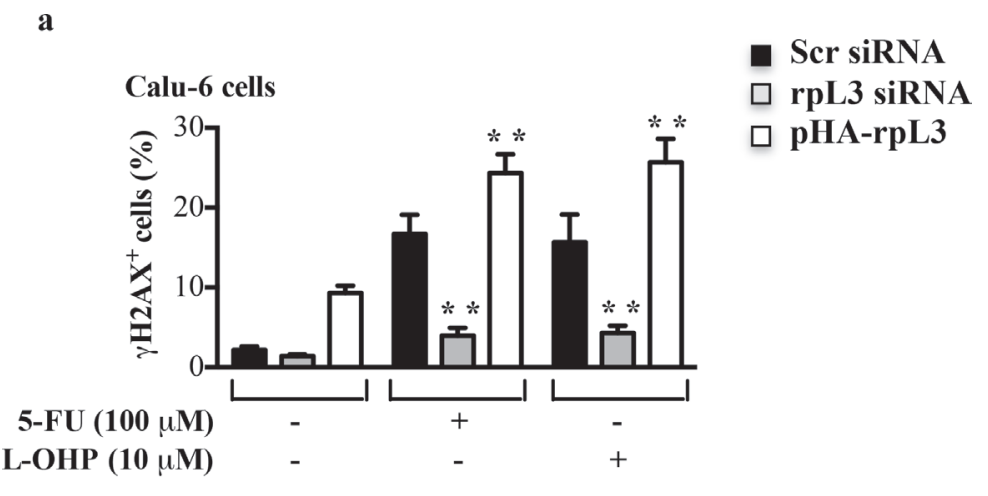

b

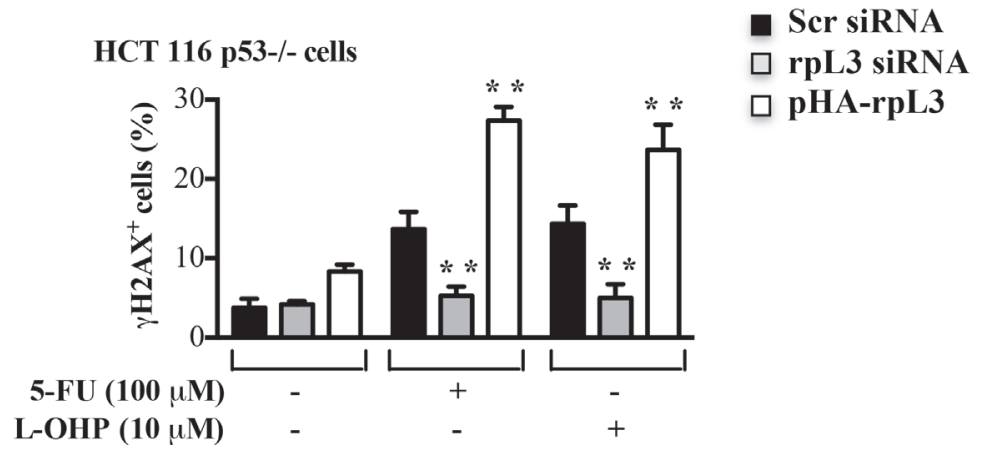

Figure 4: Effect of rpL3 on DNA damage. (a) Calu-6 cells and (b) HCT 116 p53-/- cells were transiently transfected with siRNA specific for rpL3 or scrambled siRNA (Scr) or pHA-rpL3 plasmid. Then, cell were treated with $100 \mu \mathrm{M} 5$-FU or $10 \mu \mathrm{M}$ L-OHP for $24 \mathrm{~h}$ or untreated. The samples were immunostained with an anti- $\square-\mathrm{H} 2 \mathrm{AX}$ monoclonal antibody followed by secondary fluorescein conjugate antibodies and analyzed by flow cytometry. 
a

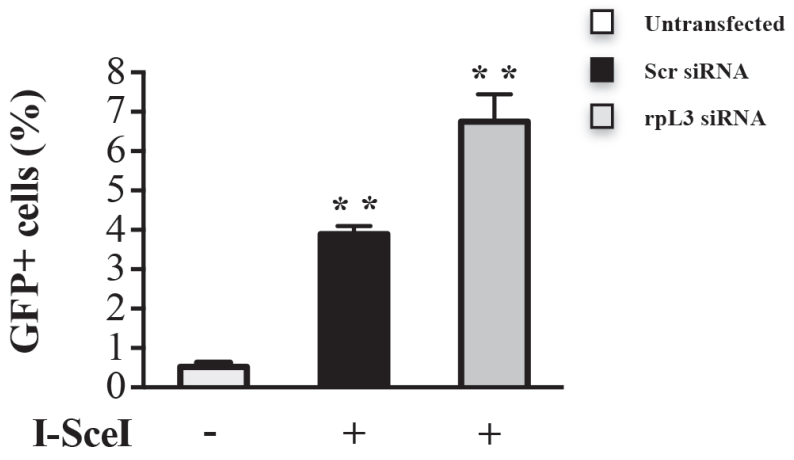

b

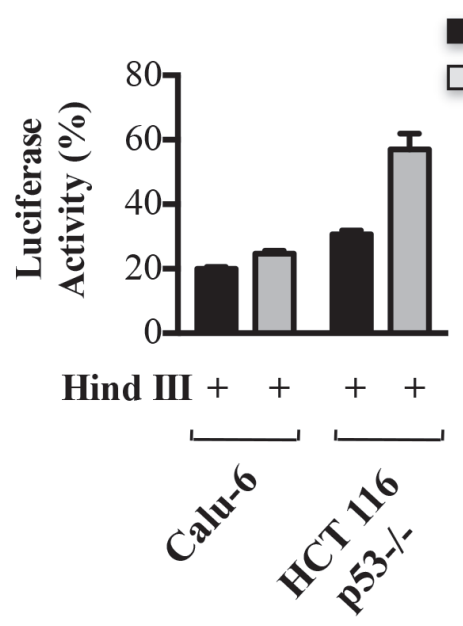

d

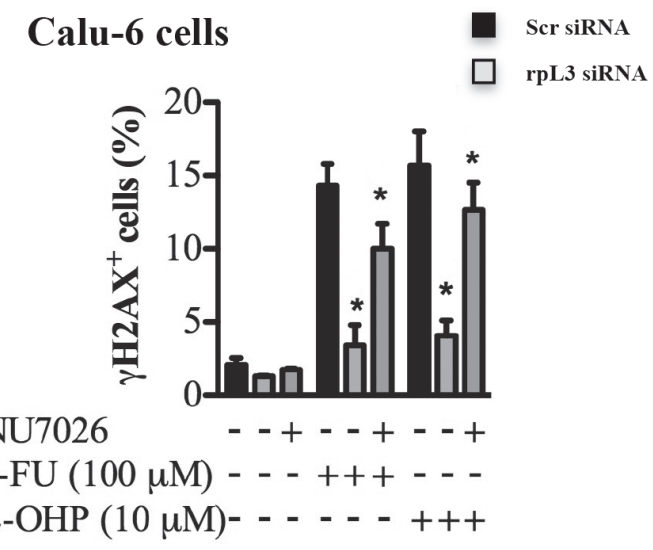

Scr SiRNA c rpL3 siRNA

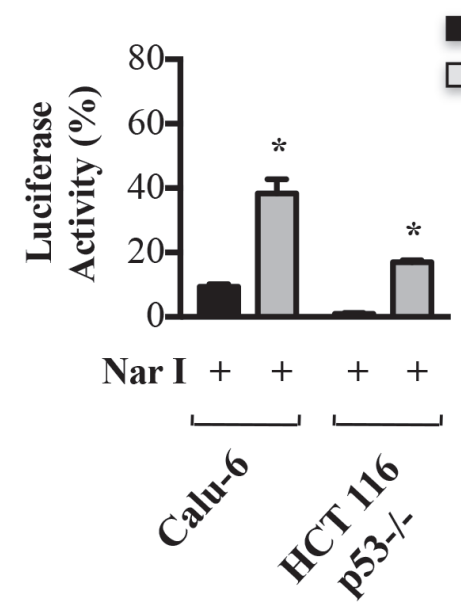

e

HCT116 p53-/- cells

Scr $\operatorname{siRNA}$

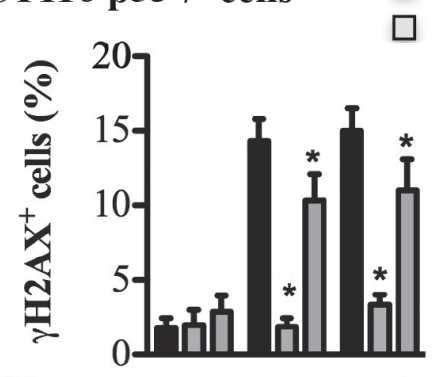

NU7026 - + + - + - +

Scr SiRNA

rpL3 siRNA

Figure 5: Role of rpL3 in the Homologous Recombination and Non-homologous End Joining. (a) HeLa/DR-GFP cells were transiently cotransfected with a plasmid expressing the I-SceI enzyme and siRNA specific for rpL3 or scrambled siRNA (Scr). $48 \mathrm{~h}$ later, cells were assayed for GFP expression by flow cytometry. Calu-6 cells and HCT 116 p53-/- cells transiently cotransfected with pGL3-luciferase linearized by the restriction endonuclease HindIII (b) or NarI (c) and siRNA specific for rpL3 or scrambled siRNA (Scr). $48 \mathrm{~h}$ later cells were analyzed for the relative luciferase activity, normalized against Renilla Luciferase (pRL). Calu-6 cells (d) and HCT $116 \mathrm{p} 53-/-$ (e) were transiently transfected with siRNA specific for rpL3 or scrambled siRNA (Scr), treated or not with $100 \mu \mathrm{M}$ 5-FU or $10 \mu \mathrm{M} \mathrm{L}-\mathrm{OHP}$ in the presence or in the absence of the DNA-PK inhibitor NU7026. $24 \mathrm{~h}$ later, cells were immunostained with an anti$\gamma \mathrm{H} 2 \mathrm{AX}$ monoclonal antibody followed by secondary fluorescein-conjugate antibodies and analyzed by flow cytometry. 
was pharmacologically inhibited by using NU7026. Then, cells were treated with $100 \mu \mathrm{M} 5-\mathrm{FU}$ or $10 \mu \mathrm{M}$ L-OHP and assayed for H2AX phosphorylation by flow cytometry. Figures 5d and 5e showed that after NU7026 treatment, 5-FU or L-OHP treatment of rpL3-depleted cells was associated to a strong increase of phosphorylated $\mathrm{H} 2 \mathrm{AX}$ levels. These results suggest that rpL3 is implicated in cell response to drugs treatment by preventing DNA repair via $\mathrm{HR}$ and $\mathrm{NHEJ}$.

\section{rpL3 regulates p21 gene transcription upon 5-FU or L-OHP treatments}

We have previously reported that rpL3 is able to control p21 promoter activity [21]. Here, we investigated whether the reported effects of rpL3 in the cell response to drug treatments were related to its ability to modulate p21 expression. To this aim, we evaluated the effect of alterations in rpL3 amount on p21 promoter activity after drug treatments. Calu-6 and HCT 116 p53-/- cells, untreated or treated with $100 \mu \mathrm{M}$ of 5 -FU or $10 \mu \mathrm{M}$ of L-OHP for $24 \mathrm{~h}$, were collected and subjected to Chromatin immunoprecipitation experiments by using anti-rpL3 antibodies and anti-IgG as control.

The presence of rpL3 in DNA-immunoprecipitated complexes was assayed by western blotting. Quantitative PCR (qPCR) assays on the samples were performed as previously reported [21]. Figures $6 a$ and $6 \mathrm{~b}$ show that in untreated cells, rpL3 is able to bind p21 promoter, as we previously demonstrated [21]. After 5-FU or L-OHP treatment, the binding of rpL3 on p21 promoter was significantly increased compared to that observed in the control.

Next, to test the role of rpL3 on p21 promoter activity in the response to drug exposure, we performed a reporter luciferase assay in condition of $\mathrm{rpL} 3$ silencing and drug treatments. To this aim, Calu-6 and HCT 116 p53-/cells were transiently cotransfected with the full-length p21 promoter luciferase reporter plasmid [21] and rpL3 siRNA or scrambled siRNA. Then, cells were treated with $100 \mu \mathrm{M}$ of 5-FU or with $10 \mu \mathrm{M}$ of L-OHP for $24 \mathrm{~h}$ or untreated and analyzed by western blotting with anti-rpL3 and anti- p21. As shown in Figures $7 \mathrm{a}$ and $7 \mathrm{~b}$ in untreated cells the rpL3 silencing did not cause any alteration on p21 promoter activity compared to untreated cells transfected with scrambled siRNA (control). The treatment with $10 \mu \mathrm{M}$ of L-OHP activated p21 promoter, while the exposure to 100 $\mu \mathrm{M} 5$-FU reduced p21 gene promoter activity.

When rpL3 expression was switched off, the effect on p21 gene transcription of $100 \mu \mathrm{M}$ of 5 -FU or $10 \mu \mathrm{M}$ of L-OHP was completely abolished since p 21 promoter activity was similar to that observed in the control (Figures $7 \mathrm{a}$ and $7 \mathrm{~b}$ ). These data indicated that $\mathrm{rpL} 3$ was necessary for regulating $\mathrm{p} 21$ promoter activity in the cell response to 5-FU and L-OHP.
We analyzed also the expression levels of p21 protein in these conditions. As shown in Figures 7c and 7d, the treatment with 5-FU caused a reduction of p21 amounts, whereas the addition of L-OHP enriched p21 levels. When rpL3 was silenced, 5-FU and L-OHP failed to exert their effects. In fact, in these conditions p21 levels resulted similar to the basal levels present in the control.

\section{rpL3 is involved in p21-dependent and p21-independent DNA repair}

To understand whether rpL3 was involved in the control of DNA repair through a molecular mechanism mediated by p21, we used p21-depleted Calu-6 (p21 $\Delta$ Calu-6) cells in which p21 gene expression was stably switched off [21]. We measured DSB formation in p21 Calu-6 cells following alterations of $\mathrm{rpL} 3$ expression levels. Cells were incubated with rpL3 siRNA or scrambled siRNA or with the plasmid pHA-rpL3. $24 \mathrm{~h}$ after transfection, cells were treated with $100 \mu \mathrm{M}$ of 5-FU and $10 \mu \mathrm{M}$ of L-OHP. Untreated and treated cells were subjected to $\gamma$-H2AX quantification to monitor DSB formation by flow cytometry. Figure 8 shows that in untreated cells, the specific depletion of rpL3 did not affect DSB formation while the ectopic expression of rpL3 induced an increase of DNA damage.

In treated cells, the silencing of rpL3 did not alter DSB levels indicating that p21 was required for the rpL3-mediated control of DNA repair. In fact, in these conditions the levels of $\gamma$-H2AX were similar to those observed in treated cells silenced with scrambled siRNA. Furthermore, in treated cells the overexpression of rpL3 was still able to increase drug-induced DNA damage. Taken together, these results indicate that rpL3 is able to control DNA repair in a p21-dependent manner as well as through mechanisms independent from p21 status of cell.

\section{DISCUSSION}

The sensitivity variation and the development of resistance limit the efficiency of chemotherapy [30]. Several preclinical studies have demonstrated that the loss of p53 function reduced cellular sensitivity to 5-FU [9] but the molecular mechanism by which this occurs is still a matter of debate [31]. A better understanding of the molecular mechanism of anti-cancer molecules such as 5-FU and L-OHP, widely used for therapy of a variety of solid tumors [32], may contribute to improve therapy based on these drugs. The results reported here extend the scenario of mechanisms of drugs as 5-FU and L-OHP that specifically impact ribosome biogenesis for the treatment of cancers lacking active p53 and highlight the importance of human rpL3 as critical mediator of cell response to chemotherapy. Data reported here demonstrate that after ribosomal stress induced by $5-\mathrm{FU}$ and L-OHP rpL3 is 
Calu-6 cells
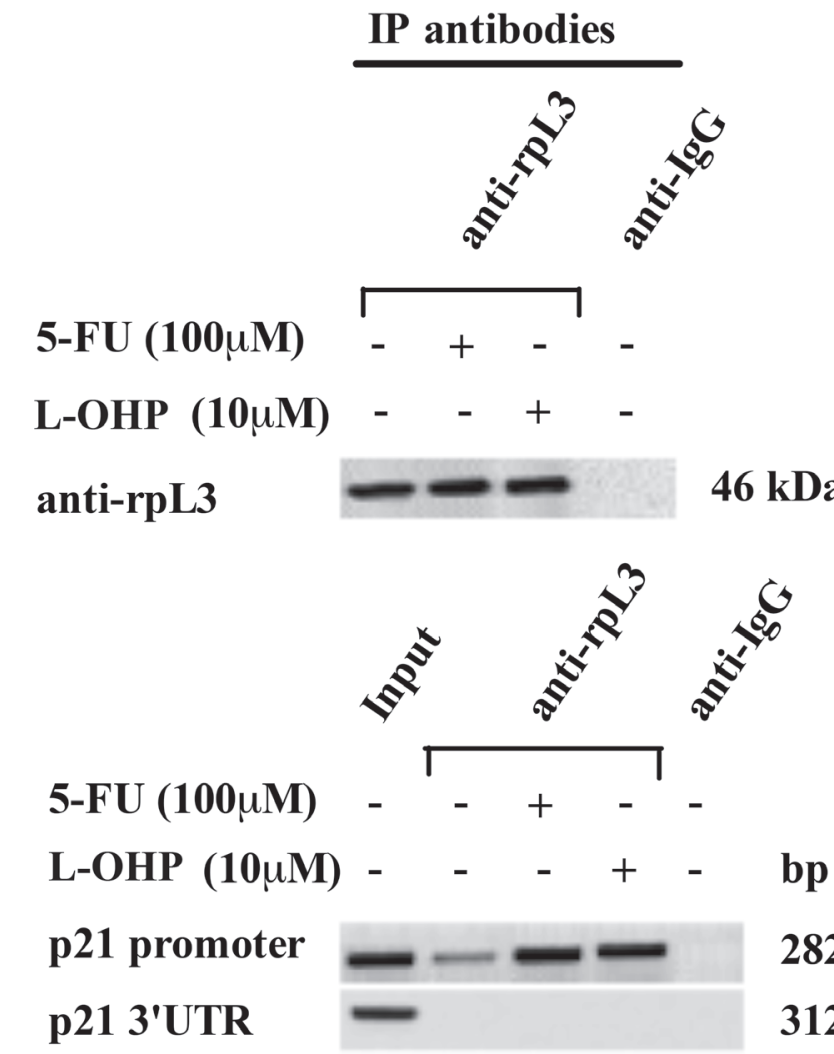

anti-rpL3

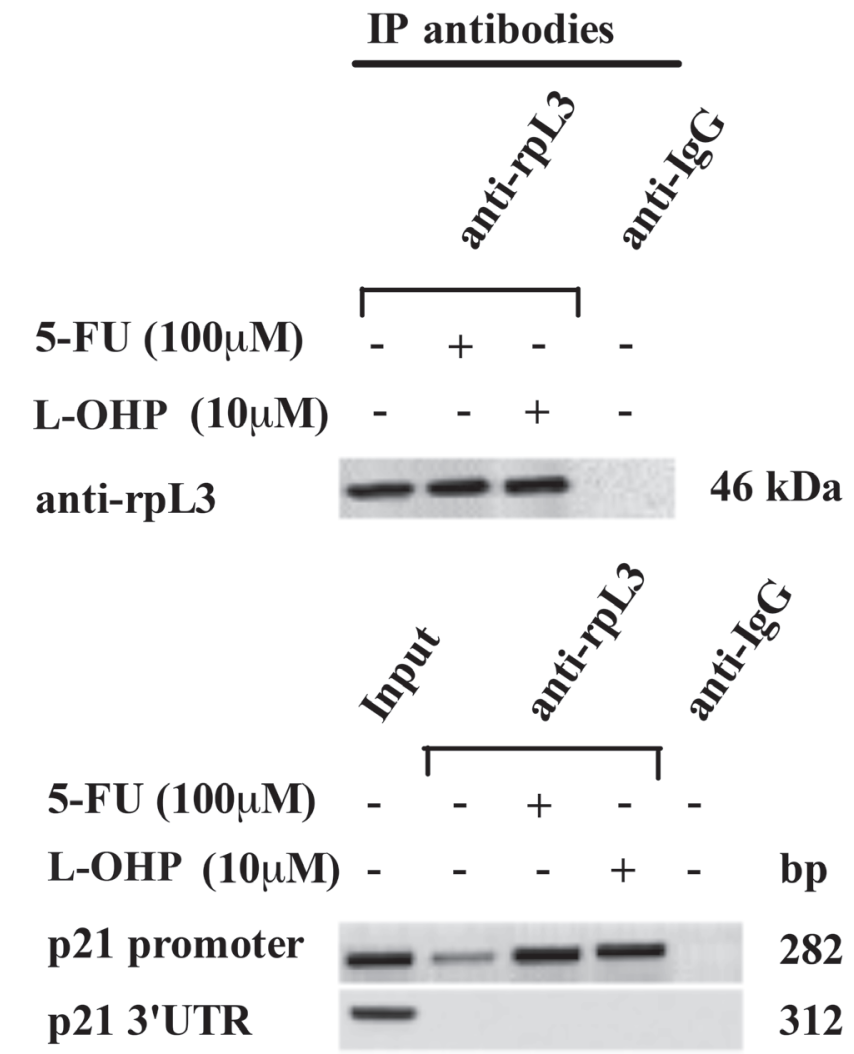

HCT 116 p53-/- cells
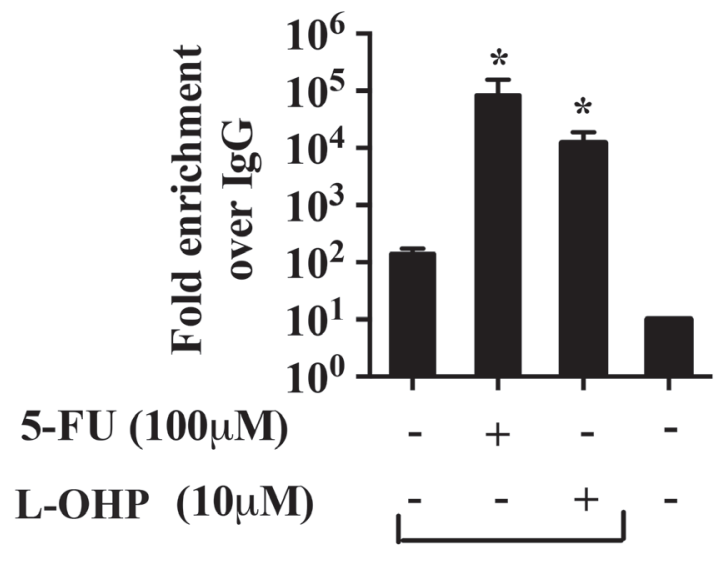

312

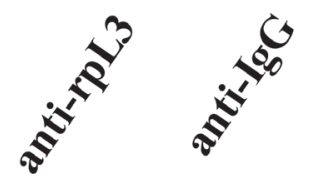

\section{IP antibodies}

5-FU $(100 \mu M)$

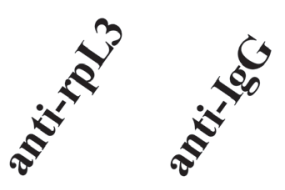

L-OHP (10 $\mu \mathrm{M})$

anti-rpL3

$46 \mathrm{kDa}$

5-FU (100uM)

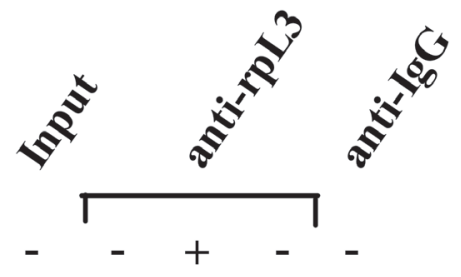

L-OHP $(10 \mu \mathrm{M})-\quad-\quad+\quad+\quad-\quad$ bp

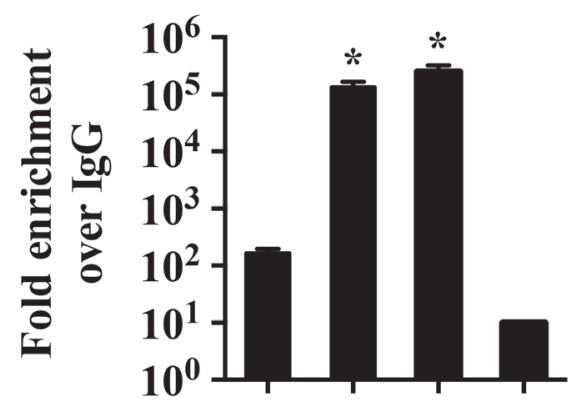

5-FU (100 $\mu \mathrm{M})$

L-OHP (10 $\mu \mathrm{M})$
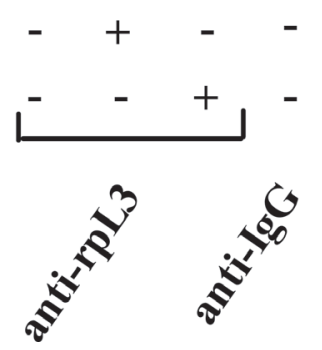

Figure 6: Analysis of the interaction between rpL3 and p21 gene promoter in response to 5-FU and L-OHP treatments. Protein samples of DNA-rpL3 or DNA-IgG immunocomplexes from (a) Calu-6 cells and (b) HCT 116 p53-/- cells untreated or treated with $100 \mu \mathrm{M} 5$-FU and $10 \mu \mathrm{M} \mathrm{L}-\mathrm{OHP}$ for $24 \mathrm{~h}$ were analyzed by western blotting assay with antibodies against rpL3. Note the absence of signal in DNA-IgG immunocomplex. The same DNA-immunoprecipitates were subjected to $\mathrm{qPCR}$ with primers specific for the proximal region of p21 gene promoter or control loci (p21 3'UTR). 


\section{a Calu-6 cells}
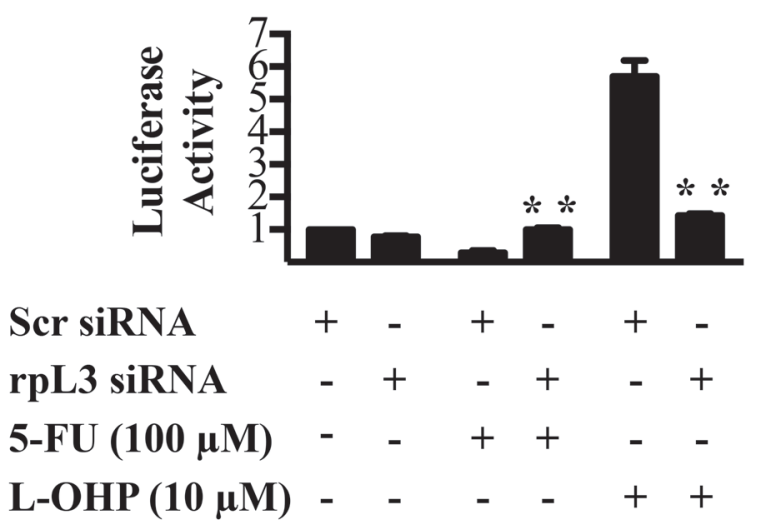

c

Calu-6 cells
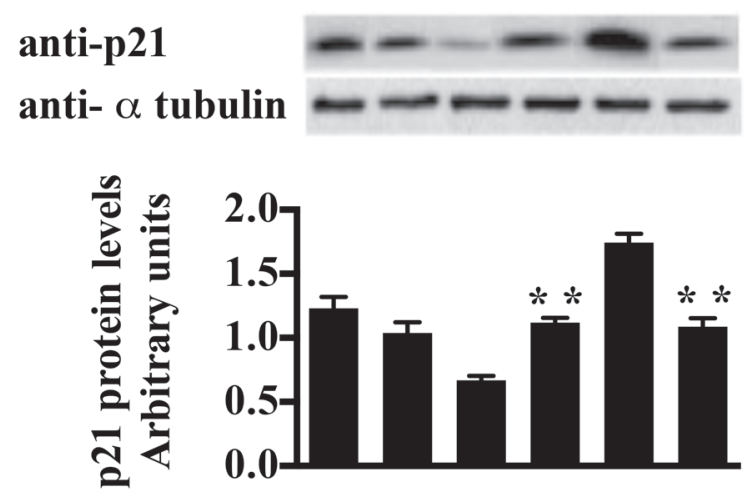

Scr siRNA

rpL3 siRNA

5-FU $(100 \mu \mathrm{M}) \quad-\quad+\quad+-\quad-$ b

HCT 116 p53-/- cells

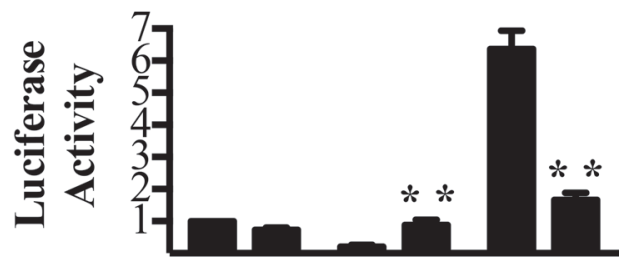

Scr siRNA

rpL3 siRNA

5-FU (100 $\mu \mathrm{M})$

L-OHP (10 $\mu$ M)

\section{d HCT 116 p53-/- cells}
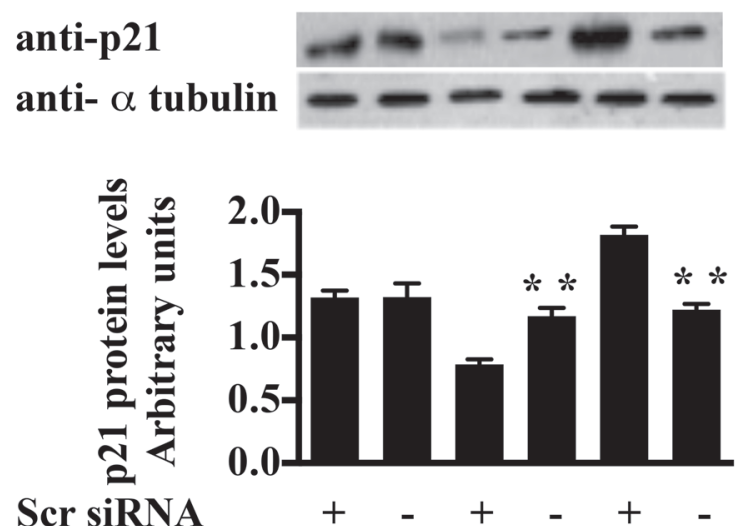

Scr siRNA

rpL3 siRNA $-+{ }_{-}+{ }_{-}$

5-FU $(100 \mu \mathrm{M}) \quad-\quad-\quad+\quad+\quad-$

L-OHP $(10 \mu \mathrm{M})$ - $\quad-\quad-\quad-\quad+\quad+$

Figure 7: Role of rpL3 in the regulation of p21 promoter activity upon 5-FU and L-OHP treatments. (a) Calu-6 cells and (b) HCT 116 p53-/- cells were transiently cotransfected with the full-length p21 promoter luciferase reporter plasmid and siRNA specific for rpL3 or scrambled siRNA (Scr). Then, cells were treated with $100 \mu \mathrm{M}$ of 5-FU or with $10 \mu \mathrm{M} \mathrm{L-OHP} \mathrm{for} 24 \mathrm{~h}$ and untreated. Analysis of the relative luciferase activity, normalized against Renilla Luciferase (pRL) activity, of the samples is shown. (c, d) Western blotting of protein extracts from the same samples with antibody directed against p21 protein. Loading in the gel lanes was controlled by detection of $\alpha$-tubulin protein.

up-regulated and accumulated as ribosome-free form (Figures 1a and 1b).

5-FU or L-OHP treatments caused a cell cycle arrest and an increase of $\gamma-\mathrm{H} 2 \mathrm{AX}$ levels indicative of a high number of DSBs [33, 34] (Figures 2a and 2b, Figures $4 \mathrm{a}$ and $4 \mathrm{~b})$. In these conditions the percentage of apoptotic cells was about 20-30\% (Figures $3 a$ and $3 b$ ) in p53 mutated and p53 null cell lines. The specific
rpL3 impairment was able to completely abolish the cytotoxic effects of either 5-FU or L-OHP. In fact, when rpL3 expression was switched off we observed a strong reduction of DNA damage following drug incubation (Figures $4 \mathrm{a}$ and $4 \mathrm{~b}$ ) and rpL3-depleted cells not only survived but became able to reenter cell cycle and proliferate (Figure 3c). In addition, the ectopic expression of rpL3 either in untreated cells or treated cells induced 


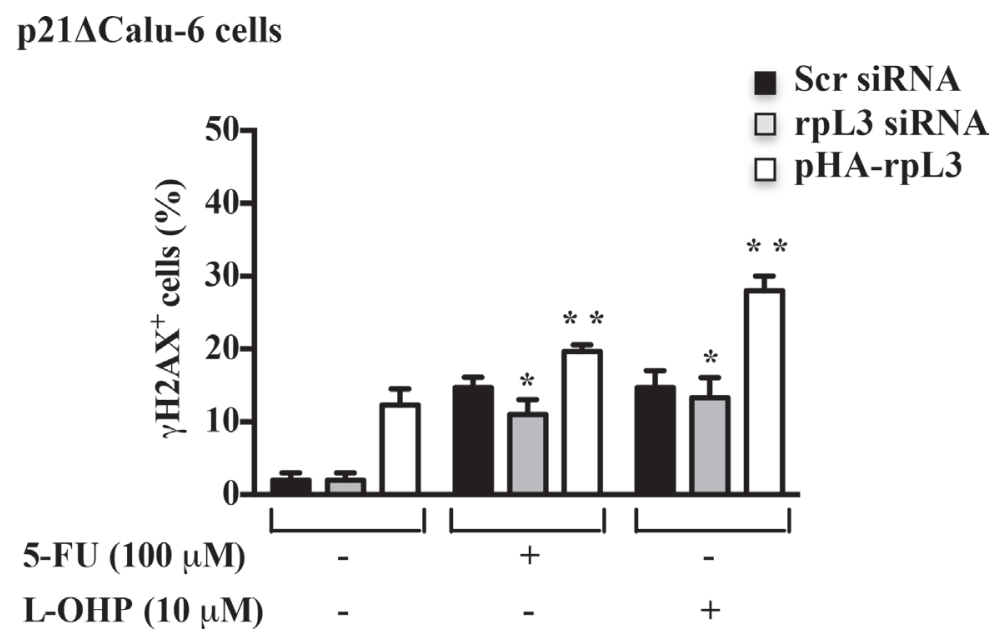

Figure 8: Role of p21 in the rpL3-mediated control of DNA repair. p21 $\Delta$ Calu- 6 cells transiently transfected with siRNA specific for rpL3 or scrambled siRNA (Scr) or pHA -rpL3, untreated and treated with $100 \mu \mathrm{M}$ 5-FU or $10 \mu \mathrm{M} \mathrm{L-OHP}$ for $24 \mathrm{~h}$ were immunostained with an anti- $\gamma-\mathrm{H} 2 \mathrm{AX}$ monoclonal antibody followed by secondary FITC-conjugate antibodies and analyzed by flow cytometry.

$\gamma$-H2AX formation (Figures $4 \mathrm{a}$ and $4 \mathrm{~b}$ ) strongly suggesting that rpL3 exterts itself cytotoxic effects leading to increase the susceptibility of tumor cells to chemotherapy.

We hypothesized that the absence of citotoxicity in rpL3-depleted cells exposed to 5-FU or L-OHP was due to an activation of DNA repair. Damage to DNA can occur in all cell cycle phases in proliferating cells and repair mechanisms involved vary in the different phases of the cell cycle $[35,36]$. Since rpL3 seems to be involved in cell response to drugs that affect different phases of cell cycle, we supposed that $\mathrm{rpL} 3$ is able to influence different DNA repair pathways. In fact, our data indicate a strong correlation between intracellular levels of rpL3 and the activity of specific DNA repair processes such as HR and NHEJ implying a significant role for $\mathrm{rpL} 3$ in the regulation of DNA repair process (Figure 5). In particular, our results show that rpL3 has a strong effect in inhibiting the precise NHEJ known as classical end joing (Figure $5 \mathrm{c}$ ).

Next, we verified whether rpL3's effect on DNA repair processes occurred through p21 involvement. Although we observed an increase of rpL3 after treatment with either 5-FU or L-OHP, a different behavior of p21 was observed. In fact, 5-FU caused a decrease of p21 protein level whereas L-OHP was able to induce a marked increase of it (Figures 7c and 7d). Data from ChIP experiments and reporter luciferase assays showed that rpL3 affected p21 expression at transcriptional level acting as transcriptional activator or repressor in response to L-OHP or 5-FU, respectively (Figures 6 and 7). Our previous experiments demonstrated the existence of rpL3-NPM complex involved in the trans-activation of p21 promoter [21]. Since it is known that L-OHP is able to promote the nucleoplasmic translocation of NPM [4] we hypothesize that after L-OHP-induced nucleolar disruption, NPM is released from nucleolus and could be recruited by ribosome-free rpL3 to form rpL3-NPM complex active in $\mathrm{p} 21$ promoter induction. In contrast, 5-FU does not induce the translocation of NPM into the nucleoplasm indicating that different protein factors could take part in rpL3-mediated regulation of $\mathrm{p} 21$ induced by this drug.

Nowadays the role of $\mathrm{p} 21$ in DNA repair has been poorly characterized [37-39]. Our results indicate that in p21-depleted cells, treated with 5-FU or L-OHP, rpL3 silencing did not cause a reduction of DNA damage indicating that $\mathrm{p} 21$ was essential for $\mathrm{rpL} 3$ role to DNA repair (Figure 8). Of interest, the ectopic expression of $\mathrm{rpL} 3$ in untreated and drug-treated p21-depleted cells was associated to an increment of DNA damage suggesting that rpL3 inhibited DNA repair also independently from p21 (Figure 8).

To our knowledge a relationship between r-proteins and inhibition of DNA repair was not described. It is plausible that upon drug-induced ribosomal stress ribosome-free rpL3 could inhibit DNA repair directly or alternatively indirectly by repressing DNA repair proteins as $\mathrm{p} 21$. The identification of DNA repair proteins involved as well as rpL3-associated factors could clarify the role of free $\mathrm{rpL} 3$ in DNA repair.

The observation that in the absence of chemotherapeutic treatments, rpL3 did not affect p21 promoter transactivation, cell cycle phases, DNA damage content and apoptosis strongly indicate that the extraribosomal function of rpL3 to control cell cycle and/or apoptosis through p21 regulation represents a pathway that is specifically activated upon drug-induced nucleolar stress.

Since reported data demonstrate that intracellular level of rpL3 can deeply influence cell response to drug treatments, the knowledge of rpL3 status in p53 null cancers may have a significant value in terms of the efficacy of chemotherapy based on 5-FU and L-OHP. 
In the light of these findings we hypothesize a working model by which the cell response to ribosomal stress caused by 5-FU and L-OHP is strongly influenced by the status of rpL3.

We predict that in physiological conditions, rpL3 primarily resides in the ribosome and the intracellular amount of ribosome-free rpL3 is functional to tightly regulate its own expression [40]. Under specific ribosomal stress (i.e. 5-FU or L-OHP treatments), rpL3 could be protected from degradation, as occurred for some r-proteins [24], and accumulates outside the ribosome. The increased ribosome-free rpL3 could translocate from nucleolus to the nucleus where it might directly affect HR and NHEJ or alternatively indirectly by modulating p21 expression levels leading to an increase of DNA damage and, consequently, cell cycle arrest and apoptosis (Figure 9).

The cytotoxic effects of 5-FU and L-OHP including DNA damage, changes in cell cycle and apoptosis, failed to occur after the loss of rpL3 leading to cancer progression (Figure 9).

In conclusion, our results add new insights to the understanding of molecular mechanisms of 5-FU and L-OHP in p53 null tumors. In particular, we demonstrate that human rpL3 acts as stress sensing molecule essential to cell response to 5-FU and L-OHP chemotherapy in cancer lacking active p53.

\section{MATERIALS AND METHODS}

\section{Cell cultures, transfections and drug treatments}

Human cell lines Calu-6 [40], p21 $\Delta$ Calu-6 [21], HCT 116 p53-/- and HeLa/DR-GFP were cultured in Dulbecco's Modified Eagle's Medium (DMEM) with glutamax (Invitrogen, Carlsbad, California) supplemented with $10 \%$ fetal bovine serum (FBS), 2 mM L-glutamine and penicillin-streptomycin $50 \mathrm{U} / \mathrm{ml}$. Calu-6 and p21 $\Delta$ Calu-6 cell medium was also supplemented with $0.1 \mathrm{mM}$ non-essential amino acids (Euroclone, West York, UK).

siRNA and plasmid transfections were performed in cells as previously described [20,21].

The siRNA targeting rpL3 was purchased from Santa Cruz Biotechnology (Santa Cruz Biotechnology, Santa Cruz, CA, USA, sc-76400).

Drug treatments were performed after siRNA or DNA transfection by adding to cells $100 \mu \mathrm{M}$ of the $5-\mathrm{FU}$, $10 \mu \mathrm{M}$ of the L-OHP or $5 \mathrm{nM}$ of ActD (Sigma-Aldrich, St. Louis, MO, USA) for $24 \mathrm{~h}$. To block DNA-PK cells were treated with $10 \mu \mathrm{M}$ of NU7026.

\section{Ribosome isolation}

Calu-6 or HCT 116 p53-/- cells were pelleted and resuspended in lysis buffer $(10 \mathrm{mM} \mathrm{NaCl}$, $10 \mathrm{mM} \mathrm{MgCl} 2,10 \mathrm{mM}$ Tris- $\mathrm{HCl}$ (pH 7.5), 0.5\% NP-40, aprotinin $1 \mathrm{mg} / \mathrm{ml}$, leupeptin $1 \mathrm{mg} / \mathrm{ml}$, pepstatin A $1 \mathrm{mg} / \mathrm{ml}$, phenylmethylsulfonyl fluoride $100 \mathrm{mg} / \mathrm{ml}$ ). After incubation in ice for $10 \mathrm{~min}$, the extract was centrifuged for $1 \mathrm{~min}$ in a microcentrifuge at a maximum speed at $4^{\circ} \mathrm{C}$ and the supernatant (total extract) was frozen in liquid nitrogen. To isolate ribosomes and ribosomal subunits, the total extracts were spun at $100000 \mathrm{~g}$ for $2 \mathrm{~h}$ on $15 \%$ sucrose cushion. After centrifugation, the pellet (which includes polysomes and ribosomal subunits) was resuspended in Loading Buffer (63 mM Tris- $\mathrm{HCl}$ pH 6.8, 5\% glycerol, 1\% SDS, 2.5\% bromophenol-blue) for western blot analysis, whereas the supernatant was precipitated with $10 \%$ trichloroacetic acid and resuspended in Loading Buffer for western blot analysis.

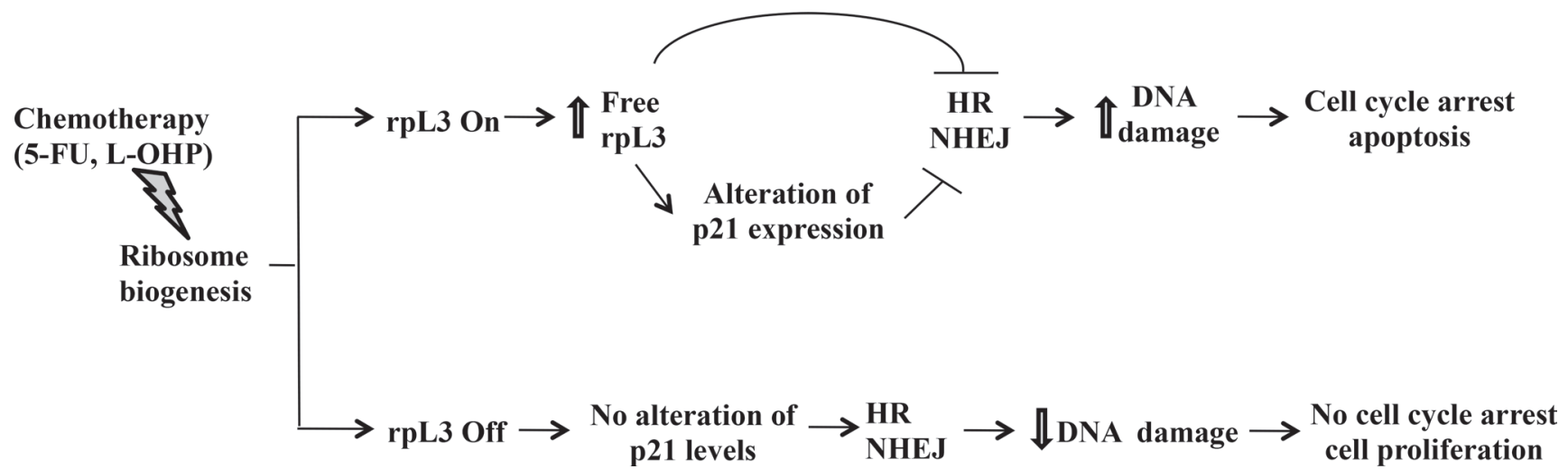

Figure 9: Schematic representation of proposed model. In the presence of rpL3 (rpL3 On), drug induced ribosomal stress caused an induction of rpL3 total intracellular levels and the accumulation of rpL3 as ribosome-free form. Free rpL3, directly and/or through alteration of p21 expression, inhibits HR and NHEJ processes leading to an increase of DNA damage and, in turn, to cell cycle arrest and apoptosis. In the absence of rpL3 (rpL3 Off), drug induced ribosomal stress did not associate to cell death. In this condition, no alteration of 21 level, HR and NHEJ were observed, cells survive and proliferate. 


\section{Western blotting}

Western blotting analysis was performed as previously reported [41]. The membranes were challenged with anti-rpL3, anti-rpL7a (Primm, Milan, Italy), antirpS19 (Sigma-Aldrich), anti-p21 (Sigma-Aldrich), and anti- $\alpha$-tubulin (Santa Cruz Biotechnology). Proteins were visualized with enhanced chemiluminescence detection reagent according to the manufacturer's instructions (Pierce, Rockford, Illinois).

\section{Chromatin immunoprecipitation}

Chromatin immunoprecipitation assay was performed as previously reported [21].

\section{Dual luciferase assay}

Luciferase assays were performed with the Dual-Glo Luciferase assay system (Promega, Madison, Wisconsin, USA) following manufacturer's instructions. Samples were read with Turner Luminometer and expressed as relative luciferase, i.e., $\mathrm{RT} / \mathrm{RC}$, where $\mathrm{RT}$ and $\mathrm{RC}$ are (Firefly luciferase)/(Renilla luciferase).

\section{BrdU incorporation}

For BrdU incorporation, Calu-6 cells or HCT 116 p53-/- cells were labeled for 40 min with $20 \mu \mathrm{M}$ BrdU (Sigma-Aldrich), harvested and fixed in $70 \%$ ethanol. Subsequently, cells were incubated with $20 \mu \mathrm{l}$ of antiBrdU-FITC antibody (BD Biosciences, Italy) for $45 \mathrm{~min}$ in dark at room temperature. Cells were then washed twice with PBS $1 \times$ and Tween $0.1 \%$, centrifuged and resuspended in $1 \mathrm{ml}$ of PBS containing $10 \mu \mathrm{g} / \mathrm{ml}$ of RNase and $5 \mu \mathrm{g} / \mathrm{ml}$ of propidium iodide (Sigma-Aldrich). Samples were analyzed by a CyAn ADP Flow Cytometer (DAKOCytomation) and quantified using Summit Software.

\section{Mitochondrial membrane potential measurement}

To quantify changes in mitochondrial membrane potential, Calu-6 cells or HCT 116 p53-/- cells were labeled with $50 \mathrm{nM}$ of the mitochondrial membrane potential-sensitive fluorescent dye TMRE (Invitrogen), for $30 \mathrm{~min}$ at $37^{\circ} \mathrm{C}$, analyzed by a CyAn ADP Flow Cytometer (DAKOCytomation) and quantified using Summit Software.

\section{Flow cytometry for $\mathrm{g}-\mathrm{H} 2 \mathrm{AX}$}

To detect $\gamma-\mathrm{H} 2 \mathrm{AX}$, cells were fixed with $70 \%$ ethanol in PBS and routinely kept at $-20^{\circ} \mathrm{C}$ overnight. Cells were washed with PBS and permeabilized with PBS, 4\% fetal bovine serum, and $0.1 \%$ Triton $\mathrm{X}-100$ for $10 \mathrm{~min}$ on ice.
Cells were incubated with anti- $\gamma-\mathrm{H} 2 \mathrm{AX}$ monoclonal antibody (JBW301 from Upstate Biotechnology), in a 1:200 dilution in PBS, 4\% fetal bovine serum, for $2 \mathrm{~h}$. Cells were washed twice with PBS-T (PBS, Tween-20 0.1\%) and incubated with 1:200 dilution of fluorescein-tagged goat anti-mouse secondary antibody (Santa Cruz Biotechnology).

After washes with PBS-T, cells were resuspended in PBS and were analyzed using a CyAn ADP Flow Cytometer (DAKOCytomation) and Summit Software.

\section{Clonogenic assays}

For clonogenic assay, Calu- 6 cells cells were plated in triplicate at $4 \times 10^{3}$ in 6 -well multidishes. After 5 to 7 days, colonies were stained with $1 \%$ methylene blue in $50 \%$ ethanol.

\section{In vivo recombination assay system and analysis of homologous recombination frequency}

HeLa/DR-GFP cells carrying a single integrated copy of GFP recombination reporter construct were kindly provided by Prof. E. Avvedimento. This reporter construct contains two GFP genes: one nonfunctional GFP gene mutated to contain a I-Scel cleavage site and an additional, truncated GFP gene that can correct the SceI site mutation. The I-SceI restriction endonuclease is used to introduce a DSB in the reporter gene. Chromosomal repair of the reporter gene by homologous recombination leads to GFP expression, which is analyzed by flow cytometry.

To examine the effect of rpL3 on DSB-induced homologous recombination, HeLa cells were transiently transfected with the I-SceI expression vector pCAGGSISceI, in the presence or in the absence of siRNA for rpL3 or scrambled siRNA. $48 \mathrm{~h}$ later, the percentage of GFPpositive cells was determined by flow cytometry using a CyAn ADP Flow Cytometer (Beckman Coulter, Inc., Milano, Italy) and Summit Software.

\section{In vivo end-joining assay}

Plasmid pGL3 basic (Promega) was linearized with HindIII (recognition site between the promoter and the luciferase cDNA) or NarI (cleaves within the coding region of the luciferase cDNA). Cells were transiently cotransfected with circular, linearized plasmid and pRLSV40 Renilla luciferase plasmid, in the presence or in the absence of rpL3 siRNA or scrambled siRNA. After $48 \mathrm{~h}$, cells were lysed in passive lysis buffer and analyzed by the dual luciferase assay (Promega). Repair efficiency was calculated from the luciferase activities of linearized reporter constructs compared with that of the intact plasmid.

\section{Statistical analysis}

Error bars represent mean \pm s.d. from $n=3$ biological replicates. ${ }^{*} P<0.05$ was considered significant, ${ }^{*} P P<0.01$ 
was considered highly significant; Student t-test is used throughout.

\section{ACKNOWLEDGEMENTS}

We thank Prof. C. Pietropaolo for critical reading of the manuscript.

This work was supported by Ministero della Università e della Ricerca (MIUR) PRIN 2010-2011, Italy

\section{Conflict of interest}

The authors declare no conflict of interest.

\section{REFERENCES}

1. Deisenroth C, Zhang Y. Ribosome biogenesis surveillance: probing the ribosomal protein-Mdm2-p53 pathway. Oncogene. 2010; 29:4253-4260.

2. Golomb L, Volarevic S, Oren M. p53 and ribosome biogenesis stress: The essentials. FEBS Lett. 2014.

3. Quin JE, Devlin JR, Cameron D, Hannan KM, Pearson RB, Hannan RD. Targeting the nucleolus for cancer intervention. Biochim Biophys Acta. 2014; 1842:802-816.

4. Burger K, Muhl B, Harasim $\mathrm{T}$, Rohrmoser $\mathrm{M}$, Malamoussi A, Orban M, Kellner M, Gruber-Eber A, Kremmer E, Holzel M, Eick D. Chemotherapeutic drugs inhibit ribosome biogenesis at various levels. J Biol Chem. 2010; 285:12416-12425.

5. Suzuki A, Kogo R, Kawahara K, Sasaki M, Nishio M, Maehama T, Sasaki T, Mimori K, Mori M. A new PICTure of nucleolar stress. Cancer Sci. 2012; 103:632-637.

6. Drygin D, O'Brien SE, Hannan RD, McArthur GA, Von Hoff DD. Targeting the nucleolus for cancer-specific activation of p53. Drug Discov Today. 2014; 19:259-265.

7. Hannan RD, Drygin D, Pearson RB. Targeting RNA polymerase I transcription and the nucleolus for cancer therapy. Expert Opin Ther Targets. 2013; 17:873-878.

8. Jamieson SM, Liu J, Hsu T, Baguley BC, McKeage MJ. Paclitaxel induces nucleolar enlargement in dorsal root ganglion neurons in vivo reducing oxaliplatin toxicity. Br J Cancer. 2003; 88:1942-1947.

9. Longley DB, Harkin DP, Johnston PG. 5-fluorouracil: mechanisms of action and clinical strategies. Nat Rev Cancer. 2003; 3:330-338.

10. Bursac S, Brdovcak MC, Donati G, Volarevic S. Activation of the tumor suppressor p53 upon impairment of ribosome biogenesis. Biochim Biophys Acta. 2014; 1842:817-830.

11. Castro ME, Leal JF, Lleonart ME, Ramon YCS, Carnero A. Loss-of-function genetic screening identifies a cluster of ribosomal proteins regulating p 53 function. Carcinogenesis. 2008; 29:1343-1350.

12. Dai MS, Zeng SX, Jin Y, Sun XX, David L, Lu H. Ribosomal protein $\mathrm{L} 23$ activates $\mathrm{p} 53$ by inhibiting MDM2 function in response to ribosomal perturbation but not to translation inhibition. Mol Cell Biol. 2004; 24:7654-7668.

13. Zhao X, Yu YT. Incorporation of 5-fluorouracil into U2 snRNA blocks pseudouridylation and pre-mRNA splicing in vivo. Nucleic Acids Res. 2007; 35:550-558.

14. Zhang Y, Lu H. Signaling to p53: ribosomal proteins find their way. Cancer Cell. 2009; 16:369-377.

15. Greenblatt MS, Bennett WP, Hollstein M, Harris CC. Mutations in the p53 tumor suppressor gene: clues to cancer etiology and molecular pathogenesis. Cancer Res. 1994; 54:4855-4878.

16. Muller PA, Vousden KH. Mutant p53 in cancer: new functions and therapeutic opportunities. Cancer Cell. 2014; 25:304-317.

17. Donati G, Montanaro L, Derenzini M. Ribosome biogenesis and control of cell proliferation: p53 is not alone. Cancer Res. 2012; 72:1602-1607.

18. Grimm $\mathrm{T}$, Holzel $\mathrm{M}$, Rohrmoser $\mathrm{M}$, Harasim $\mathrm{T}$, Malamoussi A, Gruber-Eber A, Kremmer E, Eick D. Dominant-negative Pes1 mutants inhibit ribosomal RNA processing and cell proliferation via incorporation into the PeBoW-complex. Nucleic Acids Res. 2006; 34:3030-3043.

19. Iadevaia V, Caldarola S, Biondini L, Gismondi A, Karlsson S, Dianzani I, Loreni F. PIM1 kinase is destabilized by ribosomal stress causing inhibition of cell cycle progression. Oncogene. 2010; 29:5490-5499.

20. Russo A, Catillo M, Esposito D, Briata P, Pietropaolo C, Russo G. Autoregulatory circuit of human $\mathrm{rpL} 3$ expression requires hnRNP H1, NPM and KHSRP. Nucleic Acids Res. 2011; 39:7576-7585.

21. Russo A, Esposito D, Catillo M, Pietropaolo C, Crescenzi E, Russo G. Human rpL3 induces $\mathrm{G}(1) / \mathrm{S}$ arrest or apoptosis by modulating p21 (wafl/cip1) levels in a p53-independent manner. Cell Cycle. 2013; 12:76-87.

22. Montanaro L, Trere D, Derenzini M. Changes in ribosome biogenesis may induce cancer by down-regulating the cell tumor suppressor potential. Biochim Biophys Acta. 2012; 1825:101-110.

23. Miliani de Marval PL, Zhang Y. The RP-Mdm2-p53 pathway and tumorigenesis. Oncotarget. 2011; 2:234-238.

24. Bursac S, Brdovcak MC, Pfannkuchen M, Orsolic I, Golomb L, Zhu Y, Katz C, Daftuar L, Grabusic K, Vukelic I, Filic V, Oren M, Prives C, et al. Mutual protection of ribosomal proteins L5 and L11 from degradation is essential for p53 activation upon ribosomal biogenesis stress. Proc Natl Acad Sci U S A. 2012; 109:20467-20472.

25. Sun XX, Dai MS, Lu H. 5-fluorouracil activation of p53 involves an MDM2-ribosomal protein interaction. J Biol Chem. 2007; 282:8052-8059.

26. Elmore S. Apoptosis: a review of programmed cell death. Toxicol Pathol. 2007; 35:495-516.

27. Kuo LJ, Yang LX. Gamma-H2AX - a novel biomarker for DNA double-strand breaks. In Vivo. 2008; 22:305-309. 
28. Kim JS, Krasieva TB, Kurumizaka H, Chen DJ, Taylor AM, Yokomori K. Independent and sequential recruitment of NHEJ and HR factors to DNA damage sites in mammalian cells. J Cell Biol. 2005; 170:341-347.

29. Myllynen L, Rieckmann T, Dahm-Daphi J, Kasten-Pisula U, Petersen C, Dikomey E, Kriegs M. In tumor cells regulation of DNA double strand break repair through EGF receptor involves both NHEJ and HR and is independent of p53 and K-Ras status. Radiother Oncol. 2011; 101:147-151.

30. Damia G, Garattini S. The pharmacological point of view of resistance to therapy in tumors. Cancer Treat Rev. 2014.

31. Scartozzi M, Maccaroni E, Giampieri R, Pistelli M, Bittoni A, Del Prete M, Berardi R, Cascinu S. 5-Fluorouracil pharmacogenomics: still rocking after all these years? Pharmacogenomics. 2011; 12:251-265.

32. Nielsen DL, Palshof JA, Larsen FO, Jensen BV, Pfeiffer P. A systematic review of salvage therapy to patients with metastatic colorectal cancer previously treated with fluorouracil, oxaliplatin and irinotecan $+/$ - targeted therapy. Cancer Treat Rev. 2014; 40:701-715.

33. Misset JL, Bleiberg H, Sutherland W, Bekradda M, Cvitkovic E. Oxaliplatin clinical activity: a review. Crit Rev Oncol Hematol. 2000; 35:75-93.

34. Wyatt MD, Wilson DM, 3rd. Participation of DNA repair in the response to 5-fluorouracil. Cell Mol Life Sci. 2009; 66:788-799.
35. Laiho M, Latonen L. Cell cycle control, DNA damage checkpoints and cancer. Ann Med. 2003; 35:391-397.

36. Jekimovs C, Bolderson E, Suraweera A, Adams M, O'Byrne KJ, Richard DJ. Chemotherapeutic compounds targeting the DNA double-strand break repair pathways: the good, the bad, and the promising. Front Oncol. 2014; 4:86.

37. Cazzalini O, Scovassi AI, Savio M, Stivala LA, Prosperi E. Multiple roles of the cell cycle inhibitor p21(CDKN1A) in the DNA damage response. Mutat Res. 2010; 704:12-20.

38. Abbas T, Dutta A. p21 in cancer: intricate networks and multiple activities. Nat Rev Cancer. 2009; 9:400-414.

39. Kondo S, Barna BP, Kondo Y, Tanaka Y, Casey G, Liu J, Morimura T, Kaakaji R, Peterson JW, Werbel B, Barnett GH. WAF1/CIP1 increases the susceptibility of p53 non-functional malignant glioma cells to cisplatininduced apoptosis. Oncogene. 1996; 13:1279-1285.

40. Cuccurese M, Russo G, Russo A, Pietropaolo C. Alternative splicing and nonsense-mediated mRNA decay regulate mammalian ribosomal gene expression. Nucleic Acids Res. 2005; 33:5965-5977.

41. Lavecchia A, Di Giovanni C, Cerchia C, Russo A, Russo G, Novellino E. Discovery of a novel small molecule inhibitor targeting the frataxin/ubiquitin interaction via structurebased virtual screening and bioassays. J Med Chem. 2013; 56:2861-2873. 